\title{
LCA Analysis of Greenhouse Tomato Producers' Waste Disposal Methods: A Case Study in Turkey
}

\author{
Makbule Nisa Mencet Yelboga* \\ Department of Agricultural Economics, Agricultural Faculty, Akdeniz University, Antalya, Turkey
}

Received: 7 August 2019

Accepted: 27 October 2019

\begin{abstract}
Due to rapidly growing technology in the $20^{\text {th }}$ century, the production sector achieved great progress as well as causing a serious environmental problem which we call "waste". As a major production sector, agriculture plays an important role in Turkey and creates a significant amount of waste in pre-production, production and post-production stages of agricultural outputs. Tomato production, which accounts for $48 \%$ of total greenhouse vegetable production in Turkey, is the main focus of this study since it generates a considerable amount of waste. The study uses $1 \mathrm{~kg}$ tomato produced in greenhouse conditions during a production season in 2019 as functional unit. Waste types, waste amounts and disposal method variables are taken from the tomato producers in the Antalya region who were selected by stratified random sampling method. With the scenarios created in the LCA program according to certain demographic characteristics of producers, variables are entered into the LCA program and impact assessment results are compared by using recipe methodology. Finally, the relationships between demographic criteria of producers and environmental impact results are discussed.
\end{abstract}

Keywords: waste disposal, greenhouse, tomato, LCA, Turkey

\section{Introduction}

'Waste' is defined by [1] as "a left-over, a redundant product or material of no or marginal value for the owner and which the owner wants to discard". In literature, the concept of waste is generally considered as municipal waste. [2] identifies municipal waste as waste originating from homes, commercial enterprises and public institutions to be collected and treated by local authorities.

Preventing waste before it is formed, recycling at the highest rate and disposing of it with minimal

*e-mail: nmencet@akdeniz.edu.tr damage to the environment [3] have become major issues of many international organizations, especially EU institutions. For instance, the European Union, since the 1990s, has been developing many waste treatment policies and setting many targets. Due to these policies and targets, per capita waste production in EU-28 countries decreased by 7\% from 2004 to 2012 [4]. In Turkey, 3 million tons of recyclable waste (of which $69.4 \%$ is biodegradable) are produced annually [5].

Agricultural waste is defined as the non-product output materials which result from the production and processing stages and of which beneficial use (collection, transportation, processing costs included) is more expensive than its economic value [6]. This concept also includes plastic and paper-based wastes 
(main waste inputs of this study) such as pesticide drums, fertilizer bags, trellising ropes, seedling boxes and seedling inserts besides pesticides, fertilizers, and organic waste.

Solid waste management includes generation, storage, collection, transportation, and disposal of waste [7]. In this context, LCA methodology can be implemented for environmental impact assessment of waste disposal methods and the analysis results of this assessment can provide valuable information for policy makers who are working in the field of solid waste management. For instance, some studies [8,9] have found that the landfill method has the highest environmental impact on the environment. However, in spite of its environmental costs, the landfill method is one of the most preferred waste disposal methods in the world due to its capacity, cheapness and the fact that it doesn't require high technology [10].

This study carries micro-level characteristics since the main material of the study comes from surveys directly conducted with the producers who are primarily responsible for waste disposal processes, and the results of the study are interpreted through the methods and amounts declared by them. But this study also carries meso-level characteristics since it investigates groups [11] and their waste disposal method preferences as groups.

The aim of the study is to investigate the demographic factors affecting tomato producers' waste disposal method preferences by creating different scenarios using SimaPro 7.1.8 as LCA software and Recipe 2008 methodology for $1 \mathrm{~kg}$ greenhouse tomato produced in Antalya, Turkey during a production season in 2019. Thus, by finding a relationship between the disposal method preferences and demographic characteristics, more accurate suggestions can be given to policy makers involved in waste management by interpreting the social factors affecting the waste disposal methods and stages.

\section{Materials and Methods}

\section{Study Region and Materials}

In Turkey, based on 2018 data, 48\% of greenhouse vegetable production belongs to the tomato in terms of total production amount and, when compared to other provinces, Antalya has the highest number of greenhouse cultivation areas (283 $\left.283 \mathrm{~km}^{2}\right)$ [12]. Regarding the current waste management status in the study region Antalya, according to [13], the number of solid waste disposal facilities owned by the municipality is 5 and the number of licensed packaging waste collection and recycling plants is 26. However, there aren't any non-hazardous waste (plastics other than packaging) recycling plants.

The main data of this study was obtained from face-to-face surveys from greenhouse tomato producers in Central, Aksu, Serik and Kumluca districts in Antalya. While selecting the number of producers, with the help of statistical software, the stratified random sampling method was used as the sampling method and 250 surveys were obtained. Of the surveys selected for the study, only the surveys in which the producers had given the exact amount of tomato they produced were included.

\section{Functional Unit and System Boundaries}

As a core principle in LCA studies, the functional unit provides a reference to which all inputs and

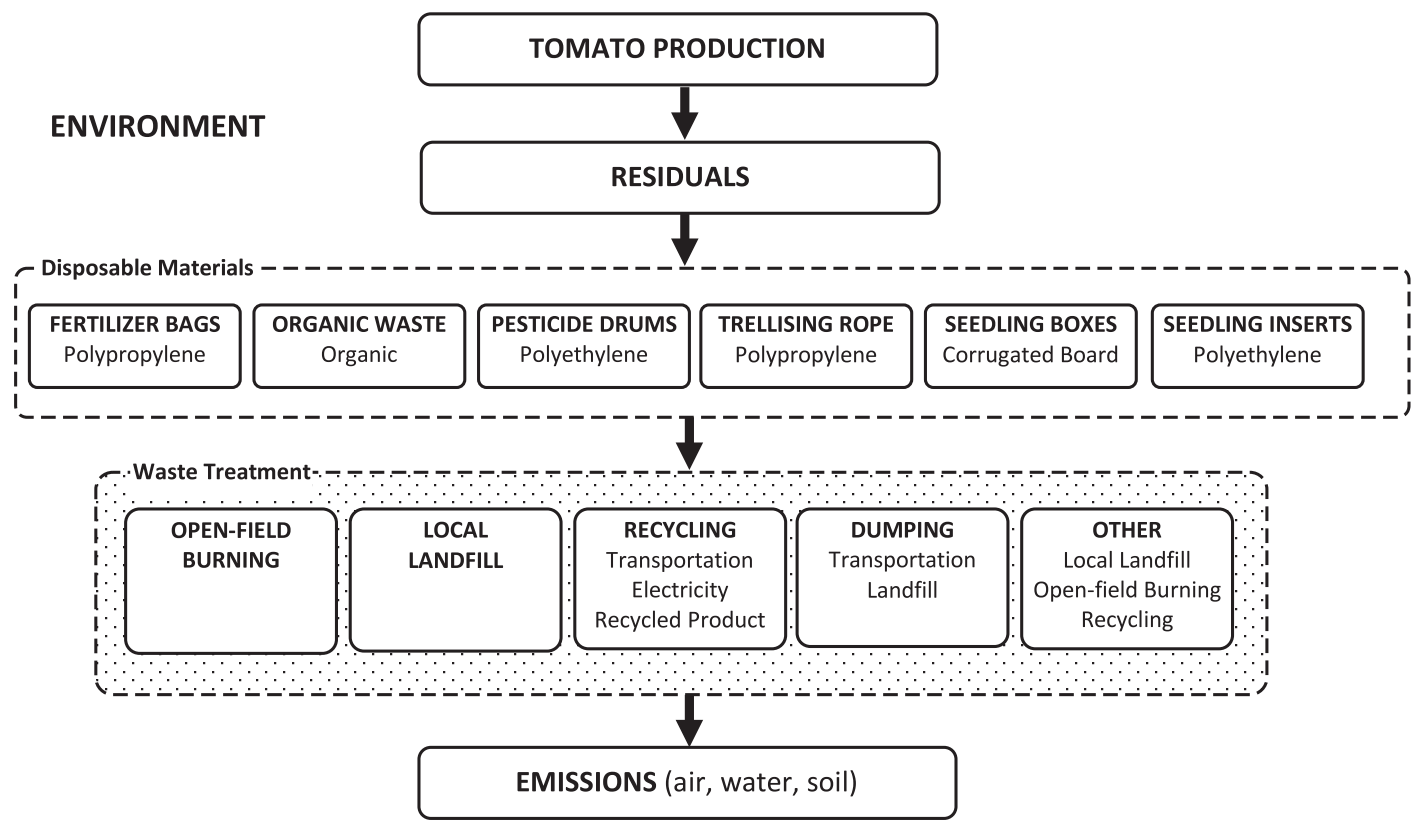

Fig. 1. System boundary scheme of the study. 
outputs are related and ensures comparability of results [14]. Especially in LCA studies about solid waste management where several scenarios were created, the chosen functional unit directly affects the implementation of LCA methodology. Accordingly, the functional unit was $1 \mathrm{~kg}$ tomato produced during one production season in 2019. This functional unit was used in the creation and comparison of scenarios in the LCA software; it was assumed that the amount of waste in the selected disposal method is formed as a result of $1 \mathrm{~kg}$ of tomato produced in greenhouses.

The system boundary period (one production season) in the study starts with the tomato seedlings being prepared for sowing and ends with the formation and the disposal of waste. The six most common waste types in greenhouse tomato production (fertilizer bags, organic waste, pesticide drums, trellising rope, seedling boxes, seedling inserts) and 5 disposal methods (incineration, landfill, recycling, dumping, other) were included in the system boundaries. Producers using incineration and landfill methods as disposal methods declared that they are disposing of the waste by using these methods. Therefore, in the study the landfill method they declared will be mentioned as local landfill and incineration method will be mentioned as "open-field burning" since they differ from municipal incineration and sanitary landfill methods.

\section{Software and Methods Used in the Study}

\section{LCA Software, LCI Database, and LCIA Methods}

SimaPro 7.1.8 was used as LCA software and Ecoinvent 2.0 was used as the LCI database in the study. All material processes are defined based on the Ecoinvent material processes and no other database was used. Also, "ReCiPe 2008 v.11 Hierarchist
Version / Average Weighting Set" was selected as the LCIA analysis method and endpoint version of it has been chosen. Additionally, normalization values are based on European normalization values.

Recipe methodology provides three perspectives: individualist, hierarchist, and egalitarian. Because it is based on the most common policy principles, the hierarchist perspective was chosen in the study. In approach level, recipe methodology comes with both midpoint and endpoint approaches which have strengths and weaknesses relative to each other. Midpoint approaches have high certainty but are less understandable, while endpoint approaches have low certainty but are more understandable to decisionmakers [15]. Therefore, the endpoint approach was followed in order to make the study more understandable for decision-makers.

In the figure below, the impact categories in the recipe 2008 method are listed under 4 titles according to the damage they cause. As the calculation unit, impact categories under the title "Damage" use DALY (disability-adjusted life year) whereas "Terrestrial Damage", "Freshwater Damage" and "Marine Water Damage" use Species.yr (loss of species during a year). But the "Fossil Depletion" category under the "Damage" title uses US dollars (USD).

\section{Other Software}

After the collection of surveys, the raw survey data were first entered into the spreadsheet software (Microsoft Excel 2013), which was also used to filter the raw data and make it ready to enter into the LCA software. Additionally, three scenarios were created with the environmental impact results of producers' waste disposal methods. For selection and distribution of subgroup criterion within each scenario, STATA 13 was used as statistical software.
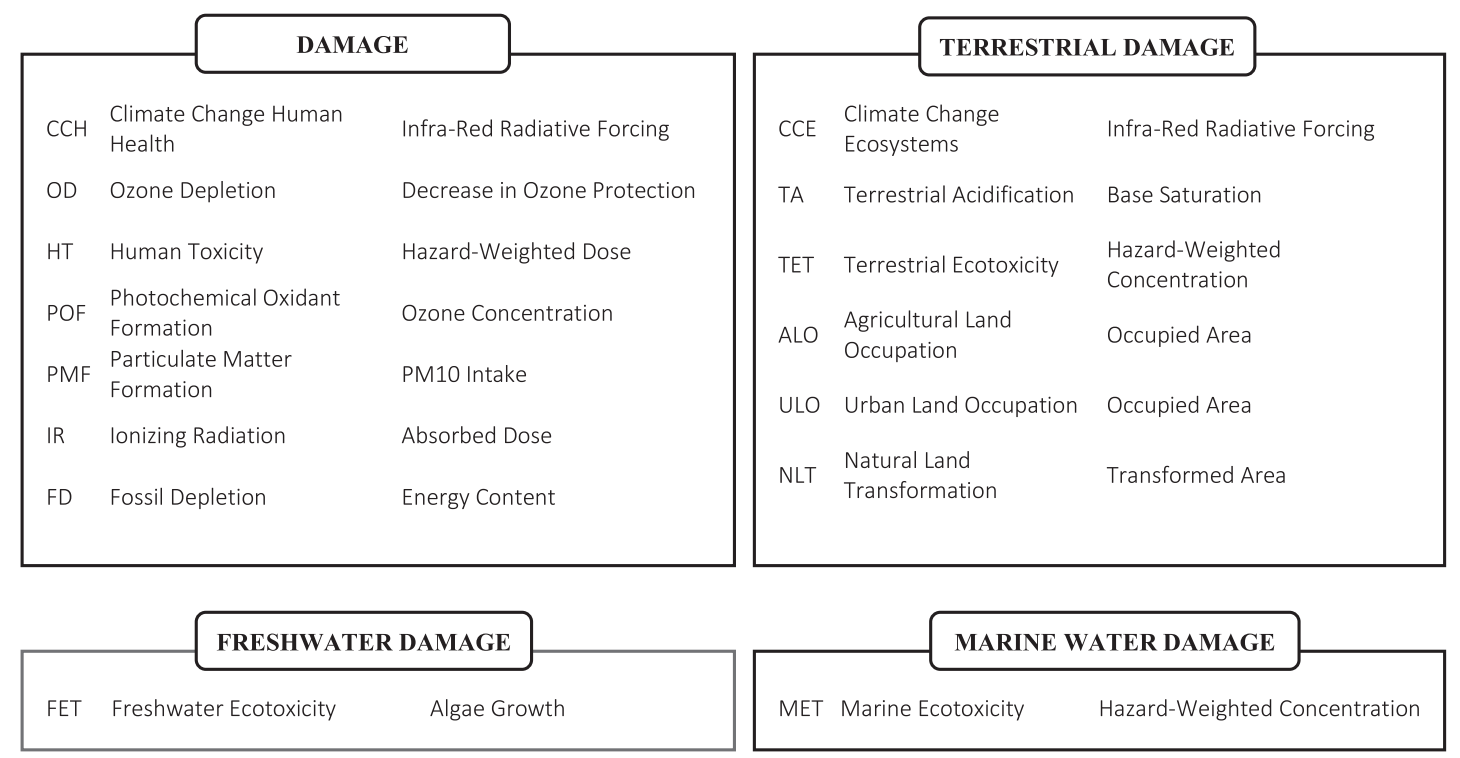

Fig. 2. Impact Categories in ReCiPe 1.11 [16]. 
Table 1. Disposable materials and their substances.

\begin{tabular}{|c|c|}
\hline Disposable Materials & Substance \\
\hline Seedling Inserts & Polyethylene \\
\hline Seedling Boxes & Packaging Cardboard \\
\hline Trellising Rope & Polypropylene \\
\hline Fertilizer Bags & Polypropylene \\
\hline Pesticide Drums & Polyethylene \\
\hline Organic Waste & Organic \\
\hline
\end{tabular}

\section{Life Cycle Inventory Categories and Processes}

\section{Input Materials to be Disposed}

Many types of waste are generated during preproduction, production and post-production stages in greenhouse tomato production. Although these waste types are common for similar greenhouse crops, the tomato was chosen because it has the largest production area as a vegetable crop in Turkey. In this study, seedling inserts, seedling boxes, trellising ropes, fertilizer bags, pesticide drums, and organic wastes (which are the most common ones) were discussed. Among the most relevant, pesticide drums are made of polyethylene material and contain the pesticides to be used in production. Additionally, organic wastes are generated during pre-production, production and postproduction stages. These organic wastes can be divided into three categories such as the plant itself, weeds, and pre-and post-harvest wastes.

\section{Disposal Methods}

Disposal methods used by the producers are classified under "open-field burning", "local landfill", "recycling", "dumping" and "other" titles.

\section{Open-Field Burning}

Open-field burning can be defined as the burning of wastes by the producers in their own land or in an empty land. It's a different process than municipal incineration, but as mentioned in [17], especially burning of plastics in an open field has serious effects on air pollution since toxic gases like dioxins, furans, mercury and polychlorinated biphenyls are released into the atmosphere.

\section{Local Landfill}

Local landfill is defined as the landfill process in which the producers bury the waste in their own land or empty land. In this method, unlike sanitary landfill, methane gas is not obtained from buried wastes. However, vegetable wastes may contribute to the breeding of undesirable diseases and pests [18].

\section{Recycling}

In recycling, the existing materials are reprocessed to make a new material so that the consumption of new materials and energy use decrease [19]. In this study, recyclable wastes are taken to the recycling centers using a transport vehicle.

\section{Dumping}

In the dumping method, the waste is transported to the municipal dump for a sanitary landfill.

\section{Other}

Some producers have stated that they use more than one disposal method for the same waste type. This disposal category is created as a separate process in the LCA software having methods stated by the producers with their percentages calculated in the spreadsheet software. Accordingly, open-field burning was $32.7 \%$, local landfill 5.9\%, recycling $27.7 \%$ and dumping $33.7 \%$.

\section{Calculation of Disposal Methods and Defining as Unit Processes}

In the LCA software used in the study, it is required to enter the mass of the materials to be disposed; this mass was calculated based on the functional unit of the study. In the spreadsheet table containing the raw data, the total amount of raw materials to be disposed of by the selected producers for the scenario was divided by the total amount of products produced by these producers and the amount of material to be disposed of for $1 \mathrm{~kg}$ of tomatoes. Considering the recycling disposal method, it is assumed that paper-based materials are recycled with a loss of $17 \%$ and plastic-based materials with a $28 \%$ loss as stated in [8].

\section{Creating Scenarios with the LCI}

Table 2 shows the scenarios and grouping criteria that have separate conditions. $56 \%$ of producers have an education level of primary school and below. The age groups $21-40,41-49,50-70$ have respective ratios of $37 \%, 32 \%$, and $31 \%$ and the experience groups $0-20$, $21-30,31-50$ have respective ratios of $41 \%, 36 \%$, and $23 \%$. Average experience of producers is 24 years and the average number of employees in the family is 3 .

In the study, three different scenarios based on the demographic characteristics of the producers were created. Through these scenarios, environmental impacts of waste disposal method preferences based on demographic factors of producers such as age, education level, and professional experience were analyzed and compared. The grouping criteria in these scenarios are determined by the help of the statistical software to ensure that each group contains as many equal surveys as possible. After the grouping criteria were 
Table 2. Scenarios and groups created for environmental impact comparison.

\begin{tabular}{|c|c|c|c|}
\hline Scenario & \multicolumn{3}{|c|}{ Groups } \\
\hline Age Scenario (years) & $21-40$ & $41-49$ & $50-70$ \\
\hline Education Scenario & Primary School and Below & Middle School and High School & University and Higher \\
\hline Experience Scenario (years) & $0-20$ & $21-30$ & $31-50$ \\
\hline
\end{tabular}

determined, producers to be included in the scenario were filtered in the spreadsheet software and the total amount of disposable material (in mass) belonging to the producers in this filtered list was entered into the LCA software for each disposal method. The material processes created in the LCA software are based on $1 \mathrm{~kg}$ of tomatoes produced in one production season, that is, the functional unit of this study. For instance, according to the age scenario, when producers between the ages of 21-40 are filtered in the spreadsheet software, the amount of polypropylene waste belonging to the "openfield burning" disposal method of the fertilizer bag was calculated as $5.25 \mathrm{~kg}$. The amount of tomatoes produced by the producers in this age group was $722000 \mathrm{~kg}$. Therefore, in the 21-40 age group, the amount of waste of polypropylene for the "open-field burning" method was calculated for $1 \mathrm{~kg}$ of tomato $(5.25 / 722000 \mathrm{~kg}$ ) and the result was entered into the LCA software. The same method was used for other disposal methods and amounts.

\section{Results and Discussion}

LCA Analysis

Overview of Waste Treatment Methods

Table 3 shows the damage assessment results of waste disposal preferences of the tomato producers without using any demographic criteria. According to these results, the dumping method has the highest score except for the freshwater eutrophication and natural land transformation categories. One of the main reasons for this is the inclusion of the process of transporting waste to the municipal dump by vehicle.

\section{Age Scenario}

Tomato producers were divided into 3 groups with equal distribution according to their ages with the help of statistical software, then the preference data of these

Table 3. Damage assessment scores of waste treatment methods for $1 \mathrm{~kg}$ tomato production.

\begin{tabular}{|c|c|c|c|c|c|c|}
\hline Cat. & Unit & Open-field Burning & Local Landfill & Recycling & Dumping & Other \\
\hline $\mathrm{CCHH}$ & DALY & $2.16 \mathrm{E}-09$ & $5.07 \mathrm{E}-12$ & $-7.89 \mathrm{E}-10(\mathrm{~L})$ & 5.39E-08 (H) & 8.52E-09 \\
\hline OD & DALY & - & - & $1.50 \mathrm{E}-14(\mathrm{~L})$ & $7.80 \mathrm{E}-13(\mathrm{H})$ & $1.21 \mathrm{E}-13$ \\
\hline HT & DALY & $1.74 \mathrm{E}-10$ & $3.35 \mathrm{E}-12$ & $1.83 E-13(L)$ & $2.07 \mathrm{E}-08(\mathrm{H})$ & $3.24 \mathrm{E}-09$ \\
\hline POF & DALY & $1.11 \mathrm{E}-13$ & $4.56 \mathrm{E}-17$ & $-1.04 E-13(L)$ & 1.19E-12 (H) & $2.14 \mathrm{E}-13$ \\
\hline PMF & DALY & $1.63 \mathrm{E}-10$ & $5.41 \mathrm{E}-15$ & $-1.36 E-10(L)$ & $1.14 \mathrm{E}-09$ (H) & $2.22 \mathrm{E}-10$ \\
\hline IR & DALY & - & - & $1.92 \mathrm{E}-12(\mathrm{~L})$ & $1.12 E-11(H)$ & $1.95 \mathrm{E}-12$ \\
\hline $\mathrm{CCE}$ & Species.yr & $1.22 \mathrm{E}-11$ & $2.87 \mathrm{E}-14$ & $-4.47 \mathrm{E}-12(\mathrm{~L})$ & 3.04E-10 (H) & $4.81 \mathrm{E}-11$ \\
\hline TA & Species.yr & $1.02 \mathrm{E}-14$ & $1.66 \mathrm{E}-19$ & $-8.79 E-15(L)$ & 6.01E-14 (H) & $1.22 \mathrm{E}-14$ \\
\hline FE & Species.yr & 4.00E-14 (H) & - & $-6.15 E-16(L)$ & $3.82 \mathrm{E}-14$ & $2.15 \mathrm{E}-14$ \\
\hline TET & Species.yr & $1.38 \mathrm{E}-14$ & $3.08 \mathrm{E}-17$ & $-1.52 E-16(L)$ & 1.13E-13 (H) & $2.27 \mathrm{E}-14$ \\
\hline FET & Species.yr & $7.86 \mathrm{E}-15$ & 4.54E-17 & $-1.14 E-16(L)$ & $1.58 \mathrm{E}-13(\mathrm{H})$ & $2.72 \mathrm{E}-14$ \\
\hline MET & Species.yr & $9.69 \mathrm{E}-16$ & 7.67E-18 & $-2.03 E-18(L)$ & 2.53E-14 (H) & $4.23 \mathrm{E}-15$ \\
\hline ALO & Species.yr & - & - & $-3.86 \mathrm{E}-13(\mathrm{~L})$ & $3.94 \mathrm{E}-13(\mathrm{H})$ & $5.43 \mathrm{E}-14$ \\
\hline ULO & Species.yr & - & - & $-1.01 E-15(L)$ & $6.76 \mathrm{E}-12(\mathrm{H})$ & $1.03 \mathrm{E}-12$ \\
\hline NLT & Species.yr & - & - & $-1.21 \mathrm{E}-14(\mathrm{H})$ & $-5.13 E-12(L)$ & $-7.83 \mathrm{E}-13$ \\
\hline FD & $\$$ & - & - & $4.81 \mathrm{E}-08$ & $9.01 E-08(H)$ & $1.95 \mathrm{E}-08(\mathrm{~L})$ \\
\hline
\end{tabular}

H: Highest Score, L: Lowest Score, LCA Method: Europe ReCiPe 1.11 Endpoint H/A (Hierarchist version, the normalization values of Europe with the average weighting set) - Damage Assessment. Abbreviations are given in Figure 2. DALY: Disability-Adjusted Life Year, Species.yr: Loss of species during a year. \$: United States Dollar. 


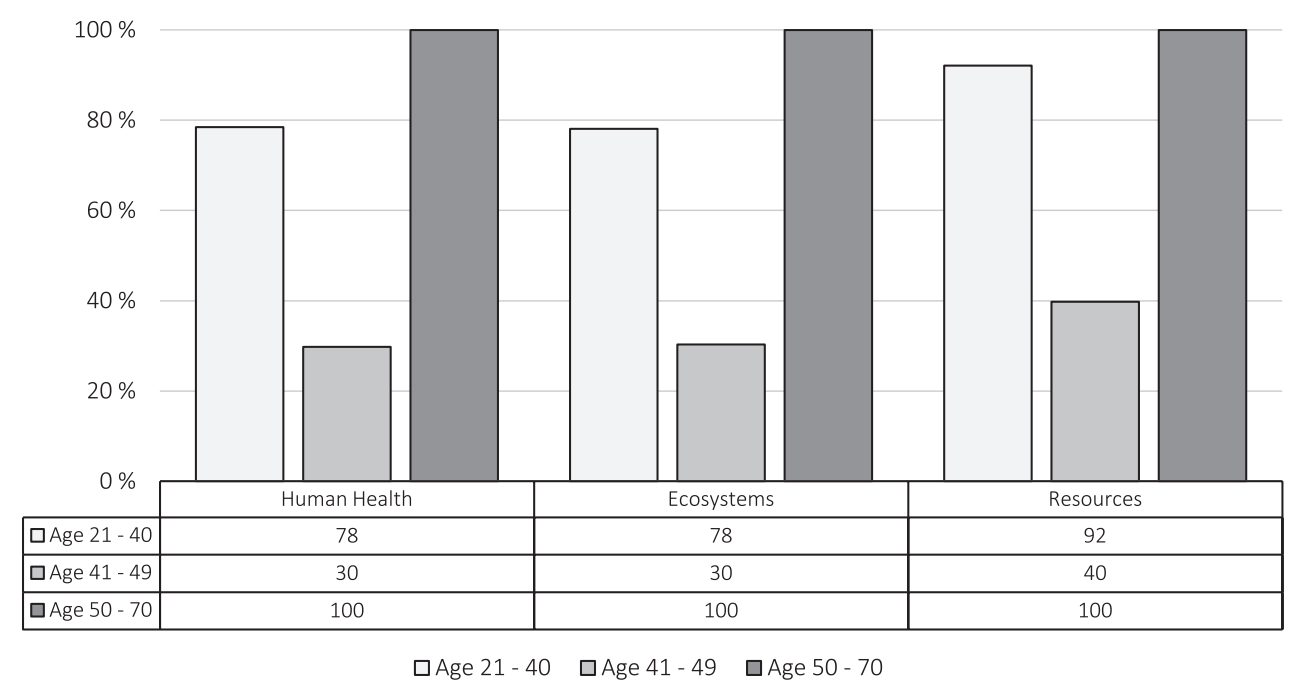

Fig. 3. Damage assessment analysis results according to age scenario.

groups were entered into the LCA software. These groups were compared using the recipe 2008 endpoint method. In Fig. 3, we assume that the percentage of the group having the highest impact assessment score is 100 and the remaining groups' percentages are proportional to the first group. As we can see, impact categories are represented in 3 main categories as resources, ecosystems and human health. In all major categories (human health, ecosystems and resources), the highest environmental impact belongs to the 50-70 age group, while the lowest impact belongs to the 41-49 age group. According to the results of this analysis, no logical relationship was found between the age group of producers and the environmental impact results of their waste disposal method preferences.

\section{Education Level Scenario}

In this scenario, similar to the previous one, tomato producers were divided into E1, E2, and E3 groups according to their education level. Then waste disposal method preferences and waste amounts of these groups were entered into the LCA software. E1 group (primary school and below) has the highest percentage in 2 main impact categories (human health and ecosystems), and the E3 group (university and higher) has the highest percentage in the other (resources) impact category. The E2 group (middle school and high school) has the lowest percentage in all impact categories. But according to the results, no logical relationship was found between the education group of producers and the environmental impact results of their waste disposal preferences. The efficiency of education system in terms of environmental sensitivity naturally affects waste disposal preferences of producers. The environmental sensitivity in the Turkish education system was studied by [20] and it was expressed that environmental awareness is not at the desired level and the effectiveness of courses should be questioned.

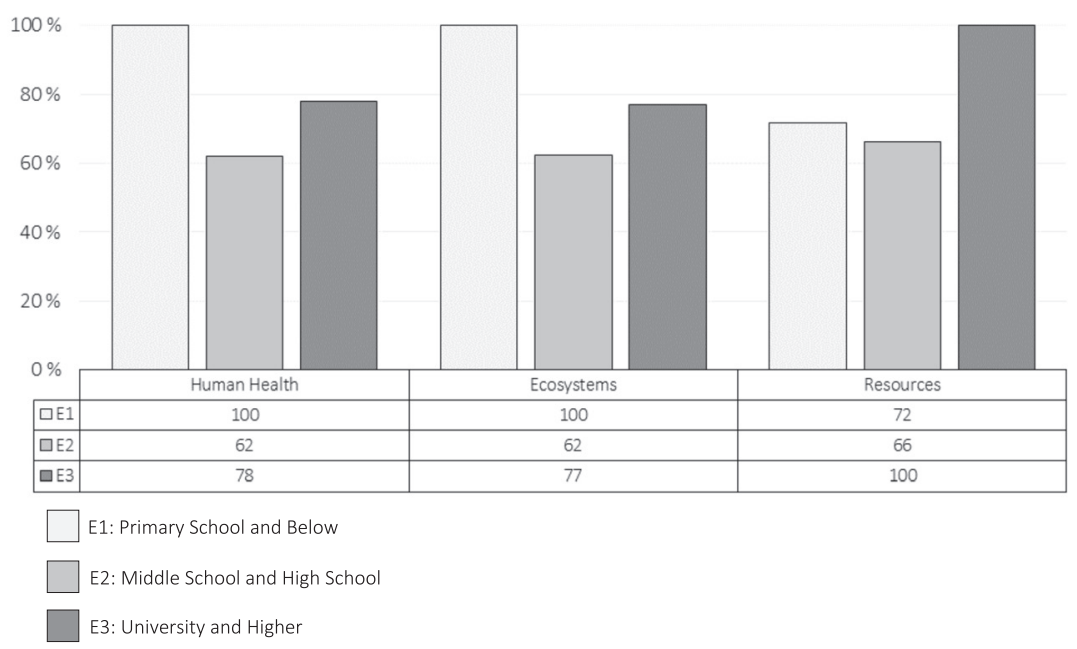

Fig. 4. Damage assessment analysis results according to education scenario. 


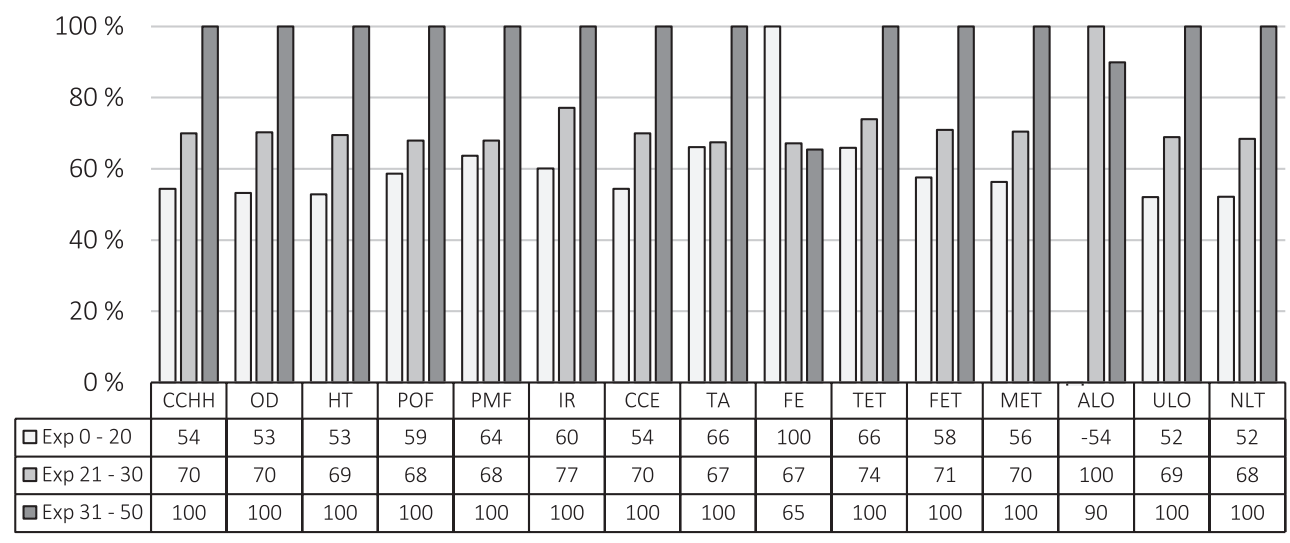

Fig. 5. Damage assessment analysis results according to experience scenario (per impact category). In the category "agricultural land occupation", the negative value of the group "Exp 0-20" is presented as " 0 "

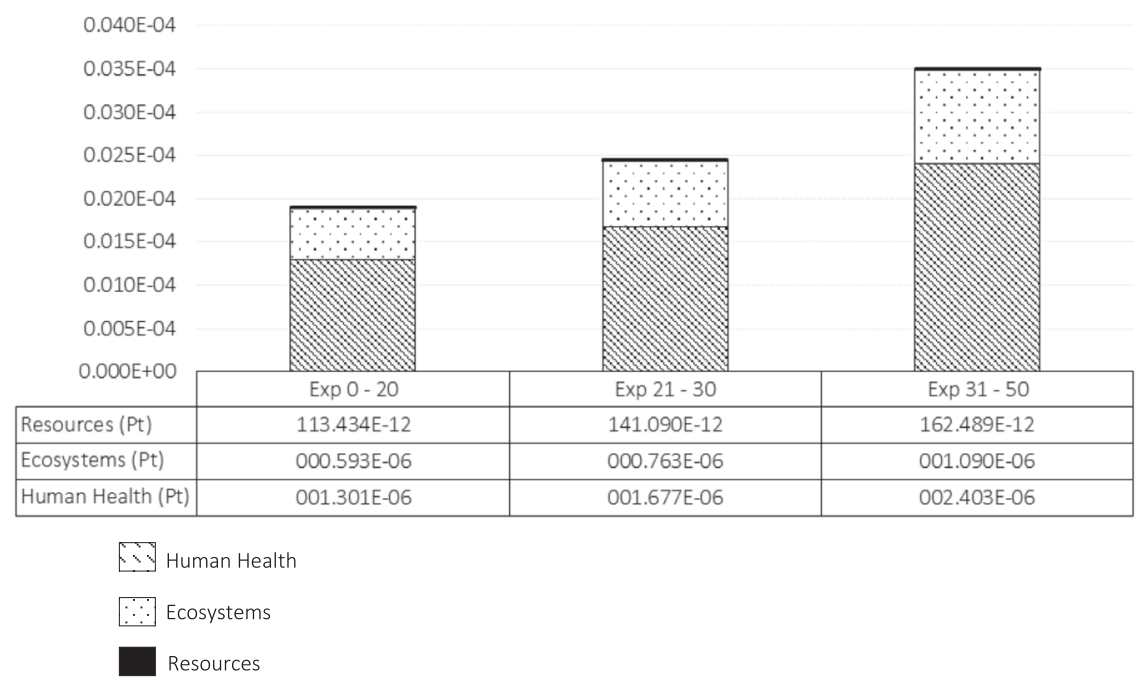

Fig. 6. Analysis results according to experience scenario (single score) - Pt. (unit): total environmental load expressed as a single score.

\section{Experience Scenario}

In this scenario, as similar to the previous scenarios, tomato producers were divided into Exp1 (0-20), Exp2 (21-30), and Exp3 (31-50) groups according to their professional experience in years. Then, waste disposal method preferences and waste amounts of these groups were entered into the LCA software. If we look at Fig. 5 to interpret the results of the analysis, in 13 out of 15 impact categories a logical relationship can be found between the producers' experience in years and the environmental results of their waste disposal preferences. Finally, when the results in Figs 5 and 6 are examined together, it can be mentioned that negative environmental effects of the waste disposal methods preferred by the new producers are less than the others.

\section{Evaluation of Scenarios}

When the LCA analysis of the 3 scenarios were evaluated as a whole, a logical relationship was found only in the third scenario (experience), whereas no relationship was detected in other scenarios (age, education). In particular, the absence of this relationship in the education scenario is also important in terms of the content and quality of the education received by the producers. When the results of the experience scenario are evaluated, it is seen that the negative environmental effects of the waste disposal preferences of the newly started producers are less than the others.

\section{Conclusions}

By means of the LCA methodology, it was investigated whether there is a relationship between the environmental results of waste disposal method preferences and the demographic characteristics of greenhouse tomato producers in 4 districts of Antalya, Turkey. Also, it was determined which waste disposal method has the highest impact and which has the lowest impact on the environment. 
At first glance, regardless of demographic characteristics of producers, it was found that the dumping disposal method (involving landfilling) has the highest impact, which agrees with $[8,9]$.

In the scenario creation phase of the study, three scenarios were created (age, education, and experience), and these have been entered into the LCA software. Accordingly, no meaningful relationship was found in the age and education scenarios; however, a relationship was found in the experience scenario. It has been concluded that new producers prefer more environmentally friendly waste disposal methods, because the new producers are more capable of retrieving up-to-date waste disposal recommendations from various sources (media, internet, books, etc.) before starting production, while experienced producers are conservative in adopting new environmentally friendly disposal methods.

The fact that no relationship was found in the education scenario can also be explained by the absence of environmental dimensions in the content of the education given to the producers. Especially when the education levels of producers in the study are considered (except for certain university departments), no courses including environmental aspects and recycling are taught or the course contents are weak. The quality of education in Turkey to effectively increase environmental awareness was also discussed in [20]. Furthermore, even if the producers receive relevant training, there is no sense of a systematic structure in which they can easily implement new environmentally friendly disposal methods.

In an environment-oriented manner, it is not an easy process to change the current behavior of rural agricultural producers who have relatively lower education levels and economic conditions than urban professions. Particularly, it is merely possible to manage waste disposal methods with more than one field - like preparation of infrastructure and education.

The preparation of infrastructure can be carried out by the construction of waste collection points that are easily accessible by the producers. Undoubtedly, the ability of the producers to transport their waste to these points without too much effort will prevent them from returning to their old disposal habits. The collected waste should then be delivered to the municipal waste recycling centers so that when this level is reached, the micro targets at the system boundary of this study are achieved. On the other hand, in the field of education, courses about recycling methods and constructed waste collection points should be provided and be made compulsory by the government. After these stages are carried out, for a sustainable waste management philosophy, it is important to continue research like this study and to determine the failures in the system in order to make the necessary interventions in time.

\section{Acknowledgements}

The author would like to thank the Scientific and Technological Research Council of Turkey (TUBITAK) for supporting the project 'Evaluation of producers' sensitivity on wastes produced in greenhouse tomato production: The case of Antalya Province" with code $217 \mathrm{~K} 206$.

\section{Conflict of Interest}

The authors declare no conflict of interest.

\section{References}

1. CHRISTENSEN T.H. Solid Waste Technology \& Management, 1 \& 2. Blackwell Publishing Ltd, 2010.

2. EEA. Managing Municipal Solid Waste: A Review of Achievements in 32 European Countries. European Environment Agency, 2013.

3. KARAGÖZOĞLU M.B., ÖZYONAR F., YILMAZ A., ATMACA E. Katı atıkların yeniden kazanımı ve önemi. pp., 2009.

4. EEA. The European Environment - State and Outlook 2015: Synthesis Report, Copenhagen, Denmark, 2015.

5. YAMAN K. Recycling of Vegetative Wastes and Their Economic Value. Journal of Forestry Faculty. 12 (2), 339, 2012.

6. NWAKAIRE J., OBI F.O., UGWUISHIWU B. Agricultural Waste Concept, Generation, Utilization And Management, 2016.

7. HARVEY P., BAGHRI S., REED B. Emergency Sanitation: Assessment and Programme Design. WEDC, 2002.

8. ERSES YAY A.S. Application of life cycle assessment (LCA) for municipal solid waste management: a case study of Sakarya. Journal of Cleaner Production. 94, 284, 2015.

9. ALI A., AZAM S., KHALID A., NOMAN D.-E.S., JAMIL N., SAMINA F., SHAIKH I.A. End- of- Life Scenarios for Municipal Solid Waste of Defence Housing Authority Lahore, Pakistan. Pol J Environ Stud. 26 (3), 961, 2017.

10. YANG R., XU Z., CHAI J. A Review of Characteristics of Landfilled Municipal Solid Waste in Several Countries: Physical Composition, Unit Weight, and Permeability Coefficient. Pol J Environ Stud. 27 (6), 2425, 2018.

11. BLACKSTONE A. Sociological Inquiry Principles: Qualitative and Quantitative Methods. Flat World Knowledge, Irvington, NY, USA, 2012.

12. TOB. Türkiye'de Örtü Altı Yetiștiricilik. Tarım ve Orman Bakanlığı, 2019.

13. ANTALYA ÇEVRE VE ŞEHİRCILIKK İL MÜDÜRLÜĞÜ. Antalya İli 2017 Y1lı Çevre Durum Raporu, 2018.

14. VAN HAASTER B., CIROTH A., FONTES J., WOOD R., RAMIREZ A. Development of a methodological framework for social life-cycle assessment of novel technologies. The International Journal of Life Cycle Assessment. 22 (3), 423, 2017.

15. ANDERSSON S., LISTÉN M. Life Cycle Impact Assessment: A comparison of three contemporary methodologies, Student thesis, 2014. 
16. GOEDKOOP M., HEIJUNGS R., HUIJBREGTS M., DE SCHRYVER A., STRUIJS J., VAN ZELM R. ReCiPE 2008: A life cycle impact assessment method which comprises harmonised category indicators at the midpoint and the endpoint level, 2013.

17. VERMA R., VINODA K.S., PAPIREDDY M., GOWDA A.N.S. Toxic Pollutants from Plastic Waste- A Review. Procedia Environmental Sciences. 35, 701, 2016.

18. PARRA S., AGUILAR F.J., CALATRAVA J. Decision modelling for environmental protection: The contingent valuation method applied to greenhouse waste management. Biosystems Engineering. 99 (4), 469, 2008.

19. GUNDA L., NLEYA M., CHISADZA Z., MANYUCHI M. Integrated Municipal Solid Waste Management System, 2016.

20. DEMIR E., YALÇIN H. Türkiye'de Çevre Eğitimi Environmental Education in Turkey. pp., 2014. 
